\title{
DA PRÁTICA À PRODUÇÃO dO CONHECIMENTO: BIBLIOTECAS NA MODERNIDADE E BIBLIOTECONOMIA PROTOCIENTÍFICA
}

\author{
FROM PRACTICE TO KNOWLEDGE PRODUCTION: \\ LIBRARIES AND PROTO-SCIENTIFIC LIBRARY SCIENCE \\ DE LA PRÁCTICA HASTA LA PRODUCCIÓN DEI CONOCIMIENTO: \\ LAS BIBLIOTECAS EN LA ERA MODERNA Y LA BIBLIOTECOLOGIA PROTOCIENTÍFICA
}

Gabrielle Francinne Tanus ${ }^{1}$

\begin{abstract}
RESUMO
A Biblioteconomia possui uma longa história, sua origem está associada às bibliotecas há milhares de anos. As bibliotecas acompanham as alterações de cada um dos períodos históricos, uma mudança significativa advém dos acontecimentos e transformações da Idade Moderna. Momento este de passagem dos livros manuscritos para impressos, o que gerou um crescimento dos acervos e, consequentemente, maiores demandas pelas atividades de organização do conhecimento. Tais preocupações em administrar, organizar, descrever, entre outras atividades, podem ser vistas nas obras produzidas ao longo dos séculos XV-XVIII, período em que a Biblioteconomia assume a denominação de protocientífica, marcada pelas normas e procedimentos técnicos.
\end{abstract}

PALAVRAS-CHAVE: Biblioteca. Biblioteconomia. Bibliotecário.

\begin{abstract}
The Library Science has a long history, its origin is associated libraries for thousands of years. Libraries accompany the changes of each of the historical periods, a significant change in its trajectory comes from the events and transformations of the modern age. This moment of passage of the manuscripts for printed books, which generated a growth of collections and consequently greater demands by organizing activities of knowledge. Such concerns in managing, organizing, describing, among other activities, can be seen in the works produced over the XV-XVIII centuries, during which the Library Science takes the name of proto-scientific, marked by the technical standards and procedures.
\end{abstract}

KEYWORDS: Libraries. Library science. Librarian.

\section{RESUMEN}

La Bibliotecología tiene una larga historia, su origen se asocia las bibliotecas durante miles de años. Bibliotecas acompañan a los cambios de cada uno de los períodos históricos, un cambio importante se deriva de los acontecimientos y transformaciones de la era moderna. Este momento de la aprobación de los manuscritos de los libros impresos, lo que generó un crecimiento de las colecciones y en consecuencia una mayor demanda mediante la organización de actividades de conocimiento. Tales preocupaciones en la gestión, la organización, que describe, entre otras actividades, se pueden ver en las obras producidas en los siglos XV-XVIII, durante el cual la Bibliotecológia lleva el nombre de protocientífica, marcado por las normas y procedimientos técnicos.

PALABRAS CLAVE: Bibliotecas. Bibliotecología. Bibliotecario.

\footnotetext{
${ }^{1}$ Doutoranda em Ciência da Informação, Mestre em Ciência da Informação, bacharel em Biblioteconomia (UFMG), e bibliotecária do Sistema de Bibliotecas da UFMG. E-mail: gfrancinne@gmail.com

Recebido em: 31/07/2015. Aceito em: 26/08/2015
} 


\section{INTRODUÇÃO}

O nascimento da Biblioteconomia, campo específico do conhecimento, está associado às origens das primeiras bibliotecas, tais instituições foram responsáveis pelas primeiras práticas e fazeres concernentes àquele ambiente. As bibliotecas acompanham as trajetórias e as mudanças do tempo em que se inserem, apresentando, assim, em cada um dos momentos da história certas particularidades que as aproximam e as distanciam. Na Antiguidade, as "bibliotecas primitivas", como as de Nippur, Ebla e Nívive, tinham como principal suporte as tabuinhas de argila. Esses registros em escritas cuneiformes eram, sobretudo, materializações de transações econômicas e administrativas. A Biblioteca de Alexandria, fundada no século III a.C, tinha como objetivo armazenar todos os conhecimentos humanos, ou, pelo menos, todos aqueles conhecidos e registrados, tornando-se um forte símbolo cultural, de poder e memória da humanidade. O papiro foi o principal suporte de escrita, mas sua escassez e impedimentos de importação levaram a cidade de Pérgamo inventar um outro suporte, o pergaminho, pele de animal curtida, mais resistente e durável do que a planta do papiro, e que perdurará ao longo da Idade Média, sendo o principal suporte do período medieval. A biblioteca de Pérgamo conhecida também pela sua importância fora saqueada pelos romanos e incorporada junto ao acervo da Biblioteca de Alexandria, que após sofrer inúmeros desastres e incêndios extingui-se, definitivamente, em 642 d.C, com o domínio dos árabes (MARTINS, 2002).

$\mathrm{Na}$ Idade Média, as bibliotecas ainda eram espaços privilegiados, destinados apenas para uma minoria que sabia ler e escrever. As bibliotecas eram subordinadas às ordens religiosas, o livro era considerado como um objeto sagrado, sendo apenas com o surgimento das universidades no século XII, que os mesmos passam a ser vistos como instrumentos auxiliares no processo educacional, nascendo, assim, as bibliotecas universitárias. As bibliotecas particulares também se faziam presentes na casa dos reis e imperadores, revelando sua riqueza e distinção. Durante estes dois momentos, Antiguidade e Idade Média, o acesso aos registros dos conhecimentos, sejam as tabuinhas de argila, os papiros ou pergaminhos, eram restritos. As bibliotecas eram instituições fechadas em si mesmas, devido ao espírito conservacionista. Os fazeres e as práticas eram norteados pelas necessidades imediatas, e não por um corpo teórico sistematizado. Desse modo, a Biblioteconomia é vista como arte ou ofício, e nomeada de pré-científica (PULIDO; MORRILAS, 2004). O desenvolvimento mais elaborado das técnicas e das preocupações com a organização, armazenamento, descrição, acesso e uso tornou-se mais intenso com o aumento crescente dos registros em papel e impressos, os quais eram produzidos nas oficinas tipográficas (MARTINS, 2002).

A prensa aperfeiçoada por Gutenberg, no século XV, com seus tipos móveis e de metal, provocou uma "primeira explosão bibliográfica" na história dos registros do conhecimento (BRIQUET DE LEMOS, 2008). O aumento da alfabetização e o barateamento do livro também são importantes para a difusão do livro, que de uma leitura intensiva passou também apresentar a leitura extensiva das obras. Em específico, este trabalho tem como objetivo olhar para as bibliotecas na Idade Moderna, um momento que rompe com o modelo de biblioteca anterior. As bibliotecas de caráter enciclopédico devido a grande quantidade de 
volumes de livros diferenciam-se das bibliotecas pouco numerosas do medievo, e que voltavam-se, sobretudo, para assuntos de cunho religioso. A biblioteca universitária que se inicia na baixa Idade Média expande seu papel na modernidade como transmissora do conhecimento, exigindo a confecção instrumentos capazes de facilitar a vida do leitor como os catálogos, que no período anterior eram vistos mais como uma lista de títulos e autores, uma espécie de inventário (PEREIRA; SANTOS, 2014).

Resgata-se, então, essa história das bibliotecas devido a relação entre os acontecimentos das bibliotecas modernas e o momento em que a Biblioteconomia se insere, nomeada de Biblioteconomia protocientífica. Essa denominação é atribuída pelos autores Pulido e Morrilas (2004), os quais classificam a Biblioteconomia em três distintos momentos: pré-científico, que vai da Antiguidade a Idade Média; protocientíco inaugurado com a Idade Moderna; e, científico a partir do século XIX. Esses momentos são assim divididos em razão das características do campo, inicialmente marcada pela prática, um fazer que antecede a teoria, depois por um saber que começa a se sistematizar, tornando-se mais elaborado e técnico, e, posteriormente, pelos traços científicos, reflexões mais elaboradas sobre bibliotecas e Biblioteconomia, refletida em diversas produções teóricas. A busca em trazer essa história das bibliotecas na Idade Moderna permite compreender melhor o processo de desenvolvimento e constituição das bibliotecas e do campo da Biblioteconomia. As produções voltadas para a biblioteca e suas questões são essenciais para a formação dos saberes biblioteconômicos, pois conhecê-los é também conhecer os antepassados da Biblioteconomia.

\section{AS BIBLIOTECAS NA IDADE MODERNA}

Com o aperfeiçoamento ${ }^{2}$ da imprensa por Gutenberg, no século XV, em Mogúncia, cidade alemã, a fabricação do livro sofreu uma mudança radical em seu processo de produção; de obras confeccionadas manualmente para obras impressas nas oficinas especializadas, e não mais nos mosteiros sob o controle da igreja católica. Esse aperfeiçoamento da impressão ocorreu devido ao uso de materiais mais resistentes para a produção de livros, como os tipos (individuais e móveis) de metais, em vez de placas inteiras e tipos de madeira, chumbo ou cobre, já utilizados pelos chineses para a confecção de livros. Contudo, apesar de Gutenberg ser a figura central no que se refere à imprensa, ele contou com o auxílio de João Furst (ourives e financiador) e Pedro Schoeffer (calígrafo de profissão), os quais à época eram sócios de Gutenberg. Essa parceria rendeu o primeiro livro impresso, em 1455, a Bíblia de 42 linhas ou Bíblia de Gutenberg, em pergaminho e em tinta a

\footnotetext{
${ }^{2}$ Os caracteres móveis já eram conhecidos na China, na Coréia, no Japão, antes de Gutenberg, por isso, não se pode dizer em invenção, mas sim em um aperfeiçoamento. Segundo Chartier (1998) o período pós-gutenberg trouxe a produção em grande escala, que no Oriente estava limitada a autorização do imperador, caracterização um modo limitado e descontínuo.
} 
óleo ${ }^{3}$. Estava impresso, assim, o primeiro livro em latim utilizando essa nova técnica de impressão, e o objeto que marca a revolução da imprensa e o início da Idade Moderna.

Segundo Burke (2002) a imprensa reproduziu uma demanda crescente no final da Idade Média, momento de pleno declínio do medievo, em que paulatinamente começou haver um crescimento da alfabetização de homens e mulheres, e consequentemente aumento da demanda de livros. Sobre essa demanda Martins (2002, p. 188) declara que "o homem adquire, através da imprensa, a plena consciência da sua força espiritual e se atira ao livro como sedento se atira à água", livros que representavam uma necessidade obscura e inconsciente e que com a imprensa torna-se consciente e lúcida. A imprensa provocou, portanto, uma revolução, na qual se equipara a pólvora, o que metaforicamente levou a uma "explosão" da produção de livros. Apesar dessa invenção, o livro assume características mais próprias da impressão apenas no século XVII. Tanto que, os incunábulos, os livros impressos nos primeiros cinquenta anos da imprensa, entre 1455 e 1500, e que se referem ao berço da tipografia, in cuna (no berço), imitavam os livros manuscritos, sendo difícil identificar o que era impresso e o que era manuscrito.

Se antes, na Idade Média, o acesso era limitado, com a imprensa o acesso passa a ser 'ilimitado', devido ao avanço da produção, o que possibilitou maiores tiragens e uma maior facilidade na aquisição, devido o barateamento no custo de produção. Contudo, como forma de controle e censura das publicações, a Igreja Católica lançou o Index Librorum Prohibitorum, ou Índice dos Livros Proibidos, no qual trazia os títulos dos livros que não deveriam ser impressos e comercializados, livros que iam contra a igreja, o catolicismo e com conteúdos julgados impróprios ${ }^{4}$. Houve também muitos temores decorrentes dessa mudança, da palavra dita em voz alta, passando pela palavra escrita manualmente para a palavra impressa, como, por exemplo, a perda do ofício dos copistas e a facilidade de acesso aos livros pelos leigos, em reivindicar sua própria interpretação, o que efetivamente aconteceu, sobretudo com os movimentos protestantes e com a tradução de diversos livros para outras línguas (BURKE, 2002; FISCHER, 2006).

Muitos dos copistas se transformaram em tipógrafos, sendo reservado o ofício manual apenas às obras destinadas às grandes personalidades. Esse crescimento acelerado dos livros ocorreu ainda em 1500. Estima-se que nos 250 centros europeus foram produzidos cerca de 27 mil edições por ano, com aproximadamente 500 exemplares cada edição e que, no século XVII, a publicação de livros baratos propiciou que mais pessoas lessem. Com efeito, a leitura não mais se restringia à Bíblia. A própria áurea sagrada, do livro como um tesouro único passou a ser paulatinamente enfraquecida. O livro tornou-se um objeto substituível, uma

\footnotetext{
3 "Desse livro foram impressos cerca de 180 exemplares, mas só restam as partes de 48 cópias, 36 impressas em papel e 12 em pergaminho. O Museu Britânico guarda dois exemplares completos em suas prateleiras" (BÁEZ, 266, p. 149). A Fundação Biblioteca Nacional, localizada no Rio de Janeiro, possui dois exemplares da Bíblia impressa em 1462, pelos sócios de Gutenberg, Furst e Schoeffer.

${ }^{4}$ Como uma medida de impedir o avanço do protestantismo, a primeira edição da lista foi promulgada pelo Papa Paulo IV, em 1559, e autorizada pelo Concílio de Trento, ficando sob a administração da Inquisição ou do Santo Ofício. A última edição do índice foi publicada em 1948 e o Index só foi abolido pela Igreja Católica em 1966, pelo Papa Paulo VI.
} 
ferramenta de acesso ao conhecimento da sociedade (FISCHER, 2006). Um século após a primeira página impressa na Alemanha, Fischer (2006, p. 212) acrescenta que um gesto simples como dobrar as orelhas dos livros, demonstra que o livro "objeto até então magnífico e precioso tornou-se enfim..., em um simples livro".

Nesse momento, o papel configura-se como um dos principais aliados na disseminação do livro impresso, em que "a principal vantagem da impressão está no baixo custo das produções em massa, as quais foram viabilizadas pelo papel, jamais pelo pergaminho" (FISCHER, 2006, p. 192). Apesar de ter sido descoberto séculos antes, por volta de 100 d.C pelos chineses, foi apenas em meados do século XV que o papel substituiria o pergaminho em quase toda a parte e torna-se um aliado do livro impresso; "com o advento da prensa, só o papel constituía no material de escrita perfeito para a multiplicação da palavra escrita por um sistema financeiramente econômico" (FISCHER, 2006, p. 192). A preocupação dos tipógrafos e impressores com os lucros das vendas dos livros acarretou uma manutenção da palavra escrita, tal como era feita pelos copistas na forma de impressão durante as primeiras décadas da invenção da imprensa, pois "como era isso que os clientes estavam acostumados a ler, era nisso que estavam dispostos a pagar" (FISCHER, 2006, p. 192), de modo que a forma da letra, os títulos, iniciais (capitulares), ilustrações e até mesmo algumas temas dos séculos anteriores se manteve presente.

Burke (2002) acrescenta também que houve mudanças no tipo de leitura, no formato dos livros, na maneira de escrever e na organização da informação, bem como o surgimento de novas ocupações. No que se refere à leitura, Burke (2002) aborda que a mesma passou de "intensiva" para "extensiva", pois o aumento quantitativo de livros já impossibilitava a leitura de toda a produção da época. $\mathrm{O}$ formato dos livros assumiu divisões como os capítulos dos livros, acréscimo de sumário, índices variados (nomes, lugares, pessoas) e notas marginais. Inclusive o livro assume um formato moderno, isto é, livros menores com folhas dobradas e com margens (MARTINS, 2002). Quanto à escrita houve um esforço de volta as "fontes" aos originais, assim como as notas de rodapé, notas inferiores e notas laterais passou a ser um novo espaço de escrita. A organização do conhecimento também sofrera transformações. Se antes eram representados por meio das árvores, com suas raízes, troncos e folhas, dando uma ideia de subordinação dos conhecimentos, com as novas classificações científicas o conhecimento passou a ser representado por meio de diagramas, estruturas mais flexíveis que mostravam as ligações entre os conhecimentos (BURKE, 2003).

"Uma análise dos currículos, bibliotecas e enciclopédias nos séculos XVII e XVIII sugerem que a reclassificação de Bacon foi a de maior sucesso entre as várias tentativas feitas à época" (BURKE, 2003, p. 90). O uso da ordem alfabética deixou de ser subordinado e se tornou de uso recorrente nas obras de referências, sobretudo, nas enciclopédias, que buscavam refletir o conhecimento da época. Mas, não foi somente a publicação de livros que cresceu vertiginosamente, Fischer (2006) aborda que as publicações periódicas se diversificaram. Sendo impressos almanaques, gazetas literárias, cadernos intelectuais, publicações médicas, notícias, anúncios públicos e propagandas. Dentre os periódicos surgidos, no século XVII, estão: Journal des Savants (1665), as Philosophical transactions 
(1665), da Royal Society, o Gionarle de' letterati (1668), de Roma, as Acta Euditorium (1682), de Leipzig, e muitos outros (BURKE, 2003).

Outra importante mudança nesse cenário tipográfico e de produção de obras impressas associa-se a mudança da marcação de propriedade nas obras. Tal marca é denominada de exlibris, os quais significam "dentre os livros de" ou "da biblioteca de...". Segundo Souza (1963) os ex-libris são tão antigos quanto os primeiros registros do conhecimento, de modo que datam da Antiguidade, sendo conhecidos registros nas tabuinhas de cerâmica do faraó Amenófis III, no século XV a.C, assim como na biblioteca cuneiforme das placas de argila do rei assírio Assurbanipal, em Ninive. Na Idade Média, os ex-libris eram feitos pelos copistas, contendo, além das iniciais ou o nome completo do possuidor, mensagens que ameaçavam com pena de excomunhão, não só os que furtavam e encobriram o furto, como aqueles que raspavam ou faziam desaparecer o ex-libris da obra roubada (BRUCHARD, 2008). Muitos dos ex-libris desse momento eram ornamentados e marcados pelas ricas imagens, aproximando-os de um caráter heráldico. Contudo, com o crescimento das obras impressas esse detalhe manual passou a ser substituído pelos ex-libris também impressos ou gravados, configurando um caráter moderno aos mesmos. Assim, sua origem remonta à Alemanha, por volta de 1450 ou 1470-80, por Johannes Knabensberg, que imprimiu uma imagem simbólica nas primeiras páginas de seus exemplares. $\mathrm{O}$ desenho de seu ex-libris era representado de um ouriço de perfil comendo flores silvestres, com o seu nome na parte superior da imagem. A partir de então várias imagens passaram a ser incorporadas como as paisagens e as alegorias, demonstrando os desejos, gostos e a profissão do proprietário das obras, sinalizando também uma distinção e até mesmo raridade da obra (SOUZA, 1963; BRUCHARD, 2008).

Nesse momento, é também de suma importância o nascimento das compilações das bibliotecas particulares ou dos "lugares-comuns", que dão origem a uma espécie de "biblioteca portátil" (BLAIR, 2000). Estes lugares-comuns constituem na reunião de obras de uma biblioteca, autores e títulos, tais como os catálogos, produzidos há séculos, ou como uma espécie de guia de conteúdos, de índice de assuntos, referências internas, citações, fatos e informações retirados de um ou mais livros, representados por um ou mais cadernos, o que facilitava o leitor e o autor na hora de construir sua obra. Sobre a construção de uma nova obra a partir de uma obra compilada por meio de várias outras anotações, Blair (2000) aponta o livro Universae Natural Theathrum (1596), de Jean Bodin, que reflete a sistematização dos fatos, leituras e observações relatadas em seu "lugar-comum". Essa espécie de caderno enciclopédico era comum na Renascença tardia e entre os homens das letras, como Shapeakare, e cientistas, como Bacon e Locke, que reúnem lugares-comuns para servir de base empírica para uma investigação sistemática e uma argumentação estruturada (BLAIR, 2000).

Ao lado dessa crescente necessidade de livros houve também uma necessária extrapolação na organização de livros, que de arcas e armários como eram armazenados no período medieval, para espaços maiores, em prateleiras e estantes distribuídos ao longo das grandes salas. Portanto, nesse momento, de difusão do humanismo e do renascimento, as bibliotecas e os livros adquirem uma importância extraordinária, de modo que "uma das 
paixões dos estudiosos é procurar em toda parte nos mosteiros ocidentais e orientais os clássicos que são redescobertos, copiados, comprados e até surrupiados" (SERRAI, 1975, p. 146). Para Burke (2003) os bibliotecários desse período moderno eram considerados como 'mediadores' fundamentais da República das Letras, o que representa uma mudança substancial na imagem do bibliotecário quando comparada com o período medieval, os quais estavam enclausurados nas instituições religiosas. Nessa mesma direção, Battles (2003, p. 123) refere-se à mudança do bibliotecário: "em lugar de simplesmente custodiar ele passou a prestar 'assistência' aos leitores".

Outra marca fundamental na história das bibliotecas, já no final da Idade Moderna, é o constante crescimento das bibliotecas privadas, que se tornou para muitos colecionadores de livros, mais conhecidos como bibliófilos, locais de contemplação e até mesmo ostentação. Segundo Cardoso (2013) "transporta-se para o interior das residências, sobretudo dos mais abastados, o modelo de estantes usados já nos grandes repositórios da corte e monásticos, nos quais se dá importância à estética e à funcionalidade na arrumação dos livros". Os livros com ilustrações e encadernações luxuosas são vistos como objetos indispensáveis de uma boa decoração residencial, bem como para a distinção do status social, sendo comuns as marcações de propriedades e preços nas obras como forma de fixação do poder. Nessa direção, cita-se a biblioteca de John Locke, que trazia em cada livro a sua assinatura e na décima primeira página de cada livro o preço respectivo, "o que facilita a percepção do valor da coleção e constitui mais um sinal provado deixado nos livros para evitar o que era e é comum ainda hoje, o furto dos livros ou o livro sem retorno depois de emprestado a alguém" (CARDOSO, 2013, p. 366).

Enfim, de modo sintético, Linares Columbié (2004) aponta outras mudanças imediatas na esfera bibliotecária como: 1) aumento da produção de impressos, o que levou ao crescimento das coleções; 2) crescimento dos acervos, que conduziu a mudanças nas edificações para abrigar essas coleções; e, 3) aumento de livros impressos, o que gerou novos meios de organizá-los e representá-los. Ainda para Martins (2002) quatro outros aspectos interligados entre si marcam as bibliotecas modernas: 1) laicização; 2) democratização; 3) especialização; 4) socialização. Segundo o autor, "a democratização é, em si mesma, um processo de laicização: a democracia é um ideário laico, por oposição ao ideário sagrado da monarquia. Mas, a democratização, que significa, igualmente, ascensão do homem comum aos privilégios que antes estavam reservados apenas a uma minoria, é, necessariamente, um processo de especialização" (MARTINS, 2002, p.324). Com efeito, a crítica ao modelo medieval, às estruturas absolutistas, assim como, a mudança no papel do livro e das bibliotecas diante dos letrados e da sociedade, foi essencial para a ocorrência do Iluminismo, movimento intelectual ocorrido na Europa, no século XVII-XVIII. A Encyclopédie (17511772), uma extensa obra cujo objetivo era arrolar a produção do conhecimento, exerceu grande influência, tal como o Iluminismo, para a eclosão da Revolução Francesa, marco inicial da Idade Contemporânea. 


\section{BIBLIOTECONOMIA PROTOCIENTÍFICA}

Como visto a partir da imprensa a produção de livros assumiu gradativamente o caráter de produto mercantil. Ao lado dessa alteração houve também a profissionalização dos tipógrafos e o rompimento do monopólio da produção bibliográfica sob as ordens religiosas, o que levou à produção de livros de assuntos diversos e em quantidade nunca antes imaginada, devido à própria limitação do homem em realizar cópias em escala maiores (ou industrial). Com o Renascimento, o interesse pela produção humana, obras artísticas, filosóficas, científicas, da Antiguidade e do momento moderno levaram a uma procura pelos livros e a confecção de novos, aumentando, inclusive as ações de colecionadores, bibliógrafos, em suas bibliotecas particulares de caráter enciclopédico. A quantidade excessiva de livros conduziu a uma necessidade de organização desse conhecimento acumulado durante os séculos, de forma que poderia ser nomeado de época dos catálogos e das classificações (ARAÚJO, 2013).

Ainda nos primeiros cinquenta anos da impressa, o editor, tipógrafo e livreiro, Aldo Manuzio, imprimiu, em 1458, a primeira classificação bibliográfica, formada por uma lista de livros em grego (libri graeci impressi) organizada em cinco classes: Gramática, Lógica, Poética, Filosofia, e Escritura Sagrada (VALENZUELA, 1998). Essa autora aponta ainda que Hernando Colón (1488-1539) produziu vários catálogos para a biblioteca de Sevilla, El registrum A e Compendium librorium, contendo inclusive índices de autores. Alejo Venegas, também espanhol, publicou em 1540 uma bibliografia geral divida em quatro ordens: original, natural, racional e revelado. Luis Vives (1490-1540), assim como os outros dois autores espanhóis, publicou Dialogistica linguae latinae exercitatio, uma obra sobre normas da biblioteca (VALENZUELA, 1998). Pulido e Morrilas (2004) destacam ainda que, advém desse momento, o primeiro catálogo dicionário da biblioteca Bodleiana de Oxford e os primeiros catálogos comerciais na feira de Frankurt.

A primeira bibliografia universal vincula-se a Konrad Von Gesner, botânico e bibliófilo, que publicou, em 1545, o catálogo Bibliotheca Universalis, em quatro volumes (3 volumes e 1 apêndice). Cada uma das doze mil obras listadas aparecem indexadas sob o autor ou o assunto, contém ainda índice por nome, sobrenome e remissiva com variantes do nome. No suplemento Pandectaruim sive partitionum universalis, de 1548, Gesner classificou os quinze mil livros por assunto, o que resultou em 21 classes, que se subdividem em seções e subseções. Além de conter um índice alfabético e palavras chaves com 25 mil entradas (SERRAI, 1975; VALENZUELA, 1998). Alonso (2006) aponta também que essa obra deveria servir de base para a organização sistemática das coleções das bibliotecas, assim como as bibliotecas deveriam usar a sua bibliografia (catalogus scriptorium) para a construção de seus catálogos (catalogus librorium), formando assim uma "biblioteca ideal". Em 1574, Gesner publica outra obra Bibliotheca Institvta et collecta primvm a Conrado Gesnero [...], que arrola "títulos de obras e nomes de autores que, segundo o inquisidor anônimo, estariam 'em danação', proibidos” (PINHEIRO, 2013). 
Seguindo a preocupação com a ordenação dos fundos da biblioteca, Federico Borromeo, cardeal italiano, escreveu a obra Constitutiones Collegii ac Bibliotecae Ambrosionae. Em 1584, foi criada a bibliografia nacional da Bibliothèque Françoise de La Croix du Maine e bibliografias organizadas por assunto no campo de teologia, direito, medicina e história como a Bibliotheca Historica de Boldanus (1620). Burke (2002) ressalta que algumas bibliografias procuravam ser abrangentes, outras eram deliberadamente seletivas. Essas obras, surgidas no século XVI, eram uma forma de resposta ao problema da explosão de livros, uma forma de se obter conhecimento dos livros produzidos por meio de um livro. Dentre as bibliografias seletivas encontram-se as temáticas, como a Bibliotheca Historica de Boldanus, publicada em 1620.

Ainda no início do século XVII, em 1605, Francis Bacon na obra Advancement of Learning, baseada no Trivium e Quatrivium, de Cassiodoro, classificou as ciências em três grupos: poesia ou ciências da imaginação; história ou ciência da memória; filosofia ou ciências da razão. Serrai (1975) aponta que os sistemas de classificação bibliográfico de Gesner e o sistema de classificação filosófico de Bacon exerceram uma influência marcante sobre os esquemas de classificação conceitual e livreira, da Encyclopedie de Diderot e D’Alembert até as categorias adotadas pela Library of Congress de Washington e a Classificação Decimal de Dewey, publicada no final do século XIX. Esse autor acrescenta ainda que as publicações de bibliografias eruditas, em particular de Tritheim no fim do século XV e a de Konrad Von Gesner permitiu um "notável impulso para a introdução, a difusão e o aperfeiçoamento das técnicas de indexação aplicadas aos catálogos por assunto" (SERRAI, 1975, p. 149). Essas bibliografias abrem caminho para a configuração de um novo campo do saber, a Bibliografia, e demonstram a relação intrínseca entre as bibliotecas, especialmente os catálogos de bibliotecas e sua organização com essas obras, as bibliografias, que visam à compilação dos saberes registrados, tal qual a biblioteca em seu espaço físico.

Gabriel Naudé, bibliotecário da biblioteca de Mazarino, é considerado o pai da Biblioteconomia moderna, devido a suas idéias expressas no manual, nomeado de Advis pour dresser une bibliothèque. Segundo Serrai (1975, p.150) Naudé foi "o maior bibliotecário do século XVII”. Para Naudé a biblioteca deveria estar a serviço de todos e ter um caráter universal com livros editados em todos os ramos do saber, nas línguas originais e traduzidos, com obras literárias antigas e contemporâneas, obras ortodoxas e heterodoxas. Além dessa visão ampliada de um acervo da biblioteca o catálogo deveria sistematizar tais obras, de forma que esse espaço não constituísse um amontoado de livros, mas uma coleção organizada que possibilitaria acesso ao acervo por todos, tal como eram nas bibliotecas públicas daquele tempo, a biblioteca Bodleiana, Ambrosiana e Angélica de Roma (está última fundada no século XVI, pelo agostiniano Angelo Rocca).

Morales López (2008) acrescenta ainda que Naudé considerava que o grande desafio dos bibliotecários era a seleção dos melhores títulos para as coleções bibliotecárias, focalizando, assim, em seu conteúdo independente de o bibliotecário estar de acordo ou não com o assunto, o que reflete uma mudança substancial no papel do bibliotecário, de guardião do saber, sobretudo, de cunho religioso, imbuindo de um espírito conservavionista, para uma 
atividade racional de seleção dos saberes em prol do outro, e não mais de uma manutenção voltada para o acervo, para a custódia das obras armazenadas nas bibliotecas. A biblioteca ganharia assim o adjetivo moderno, sendo a biblioteca moderna formada pela relação entre o acervo, os leitores e a biblioteca, onde os profissionais, bibliotecários, possibilitavam o encontro/mediação entre os livros e os usuários.

Segundo Nells (2000), Gabriel Naudé foi influenciado pela obra De bibliothecis syntgma, escrita em 1602, com segunda edição em 1607, por Justo Lípsio. Essa obra pode ser considerada como o primeiro estudo monográfico sobre as bibliotecas da Antiguidade, que serviu como modelo para os mecenas, os bibliotecários e os eruditos de seu tempo (NELLS, 2000). Lípsio, um dos sábios mais famosos do século XVII sobre a Antiguidade Clássica, definiu o termo biblioteca como: 1) local ou edifício; 2) coleção de livros; 3) livro que referencia outros livros, uma espécie de bibliografia. Em seus onze capítulos reflete sobre a localização das bibliotecas na Antiguidade, geralmente nos templos, os mobiliários e a decoração da biblioteca, compostas por esculturas dos autores, que ajudavam ambientar o leitor, e a questão da meditação nas bibliotecas (lugar de erudição e pesquisa, sem finalidade pedagógica e orientação confessional) (NELLS, 2000). Diferentemente desse espírito, Gabriel Naudé defende que a decoração da biblioteca deve ser desprovida de qualquer ornamento como as estátuas de autores, como defendia Lípsio, pois para ele a figura central da biblioteca, o livro, não deve ser ofuscada por outros objetos (ALONSO, 2006).

Para as bibliotecas particulares, em matéria de classificação bibliográfica, tem-se o esquema de classificação denominado "sistema de Araoz", devido ao seu autor Francisco de Araoz, que publicou a obra De Bene Disponenda Bibliotheca, ad meliorem cognitionem loci \& materiae, qualitatisque librorum, litteratis perutile opvscvlvm, em 1631. Em 1635, outro manual de Biblioteconomia, datado da primeira metade do século XVII, de Clément Claude, nomeado de Musei sive Bibliothecae tam privatae quam publicae extructio, instructio, cura, usus libri IV traz a influência de Lípsio (da biblioteca com templo de sabedoria e da riqueza decorativa do espaço, mas com um novo significado, ajustando ao pensamento contrareformista) e de Antonio Possevino (jesuíta, contra-reformista, autor bibliografias com obras que os leitores católicos, norteado pela igreja, deveriam conhecer, constituindo a ideia de biblioteca ideal). Clément Claude afastava radicalmente das idéias e Naudé, que defendia a biblioteca como espaço para todos, sem a interferência ideológica ou censura, enquanto para Claude desde a entrada na biblioteca o leitor deveria sentir o clima da verdadeira religião, através dos livros, do mobiliário e da decoração pictória e esculturas, carregadas de efeito moralizante em prol do catolicismo (ALONSO, 2006). Essa obra do jesuíta Claude visava atender às necessidades culturais do homem católico, tendo em vista a instalação da biblioteca do Colégio Imperial, pela Companhia de Jesus, ou seja, era um manual dedicado ao monarca espanhol Felipe IV (ALONSO, 2006).

Naudé, em 1643, lança um novo sistema de classificação, na obra Bibliotheca Cordesiane Catalogus, que abrangia 12 classes (Teologia, Medicina, Bibliografia, Cronologia, Geografia, História, Arte Militar, Jurisprudência, Direito, Filosofia, Política e Literatura). No ano seguinte, em 1644, Louys Jacob, publica a obra Traicté des plus belles 
bibliothèques publiques et particulières qui ont esté et qui sont à présent dans le monde, divisé en deux parties, a qual pode se considerar como a segunda obra que aborda a temática da história das bibliotecas como objeto de estudo, tal qual realizou Justo Lípsio. Na segunda metade do século, exatamente em 1650, o puritano John Dury, nome importante na Revolução Puritana da Inglaterra, escreveu a obra The reformed Library Keeper, com o objetivo de preparar para o novo século as reformas do conhecimento, para ele as bibliotecas as escolas e as igrejas são componentes fundamentais para um mundo melhor, se devidamente reformadas. Em especial, as bibliotecas não devem servir apenas para guardar os livros, mas para torná-los disponíveis para aqueles que procuram o conhecimento universal e compreensão do Reino de Deus. Assim, a biblioteca e o guardião da biblioteca podem desempenhar um papel importante na tomada do conhecimento disponível.

Com o já crescente registros do conhecimento, foram criadas, no ano de 1660, as resenhas de livros publicadas nas revistas eruditas, como na Philosophical Transactions da Sociedade Real de Londres e no Journal des Savants de Paris (a revista científica mais antiga da Europa, criada em 1665, sob a forma de boletim de doze páginas, onde anunciava o objetivo de fazer conhecer o que acontecia na República das Letras). Como forma de inspiração desse primeiro periódico foi criado duas décadas depois, em 1682, na Alemanha, o seu primeiro periódico científico, Acta Erudictorum, tendo como primeiro editor Gottfried Wilhelm Leibniz. E, em 1684, foram lançadas no Nouvelles de la Republique des Lettres, de Amsterdã, as primeiras crítica literária do jornal. Sobre as bibliografias de bibliografias temse a obra Bibliotheca bibliothecarum curis secundis auctior, de Philippe Labbé, publicada em 1678, cuja primeira edição data de 1664. Para Pinheiro (2013) essa obra é uma espécie de metabiblioteca, uma biblioteca de bibliotecas que apresenta extraordinária biobliografia de organizadores de catálogos bibliográficos. Nessa direção, Jean de la Caille, publicou em 1689, Histoire de l'Imprimerie et de la Librairie, obra que consiste em uma biobliografia de tipógrafos e impressores europeus desde o advento da tipografia até 1689. Cada verbete apresenta uma breve biografia do tipógrafo ou impressor e arrola os autores e obras que publicou (PINHEIRO, 2013).

$\mathrm{Na}$ Inglaterra, em 1697, Thomas Bray publicou Essays towards promoting all necessary and useful knowledge, both divine and human, in all parts of his majesty's dominus, obra que seria uma espécie de precursora de uma preocupação com o uso efetivo dos recursos (no caso apenas livros e documentos impressos) contidos na biblioteca (ARAÚJO, 2013). Na Alemanha, Johann Christian Koch publicou, em 1713, Schediasma de ordinanda bibliotheca, em que o funcionamento da biblioteca atende a dois tipos de tarefas, uma de ordem externa, referida à seleção e colocação dos livros, outra de ordem interna, relativa à preparação de índices e catálogos. Para Koch estas últimas atividades são puramente biblioteconômicas, enquanto as primeiras podem ser executadas por alguém que não necessariamente é um bibliotecário (PULIDO; MORILLAS, 2004). Valenzuela (1998) aborda também as publicações de Giovanni Rhode, Hypotysis bibliothecae publicae (1733), de Giulio Cesare Becelli, Bibliotheca instituenda et ordinanda (1747) e as classificações sistemáticas, em quatorze classes de W. London, e cinco classes de Garnier. 
Outra obra que expressa a sistematização do conhecimento é a Encyclopédie, ou dictionnaire raisonné des sciences, des arts et des métiers, editada por Direrot e D'Alembert, na França. Essa enciclopédia moderna é composta por 33 volumes e mais de 71 mil artigos, os quais foram escritos por mais de 200 colaboradores, entre eles figuras notáveis como Voltaire, Rosseau, Montesquieu, homens que também estavam vinculados ao Iluminismo. $\mathrm{O}$ primeiro volume foi publicado em 1750 e o último em 1772, por questionar o antigo regime e a igreja católica a obra era constantemente interrompida pela censura da época. Tal como demonstrou Burke (2003), ao escrever sobre a reestruturação das bibliotecas, currículos e enciclopédias, que passaram a utilizar as classificações como meios de classificar suas coleções e os conhecimentos, cita a Enciclopédia francesa que usava o esquema de Bacon, composta por três ramos: Memória/História, Razão/Filosofia, e Imaginação/Poesia.

O alemão Daniel Georg Morhof apresenta no livro Polyhistor, Literarius, Philosopchicus et practicus, de 1732 (4 $4^{\text {a }}$ edição), a figura do Bibliothecarius, como um homem erudito, formado por uma mente crítica devido a leituras extensivas de livros em todos os ramos do saber, o que lhe permite conhecer a coleção e o capacita na indicação de livros para os leitores da biblioteca (MORALES LÓPEZ, 2008). Em 1756, Jean-HenriSamuel Formey, publica a obra Conseils pour former une bibliotheque peu nombrevse mais choisie, que se volta para o colecionador particular dando conselhos sobre como formar uma coleção. Nessa obra, o autor propõe um catálogo de livros considerados essenciais nas bibliotecas particulares instituídas sob o Antigo Regime (PINHEIRO, 2013).

Sobre o bibliotecário, Cotton des Houssayes, realiza um discurso em latim na Assembléia Geral de Sorbone, em 1780, intitulado Oratio habita in Comitiis Generalibus Societatis Sorbonicae. Neste trabalho ele esboçou o que considerava ser em as atribuições e qualificações de um bibliotecário. Assim, para o autor, o bibliotecário deve possuir toda a aprendizagem secular e sagrada; ser um teólogo profissional, e ter uma série de conhecimento de literatura, das artes e das ciências. Ele deve ser versado em bibliografia, uma vez que é a base de todas as outras ciências. O bibliotecário deve ter bom senso na aquisição de livros e tem a capacidade de criar uma coleção abrangente, mas ele deve praticar seleção para alcançar mérito genuíno para sua biblioteca. O bibliotecário deve exercer economia; deve estar imbuídos da necessidade de um bom sistema de classificação; e ter uma grande memória, pois ele deve conhecer todos os livros e sua localização. Um bom bibliotecário deve acolher todos os estudiosos e será o seu guia amigável e inteligente. Ao introduzir um patrono para a biblioteca, ou se um estudioso deve pedir para ver um livro, ele deve ser colocado diante dele. O bibliotecário deve estar sempre pronto com sugestões de outros livros sobre o mesmo assunto. Por fim, o bibliotecário deve ser educado, erudito e oferecer um excelente serviço para seus leitores.

\section{CONSIDERAÇÕES FINAIS}

A Biblioteconomia possui uma imbricada relação com a história das bibliotecas, ambas estão interligadas ao contexto político, econômico, cultural e social de cada momento histórico. Esse resgate diacrônico permite compreender o processo de formação e 
desenvolvimento tanto das bibliotecas, da biblioteconomia e da figura do bibliotecário na Idade Moderna. Anterior ao período aqui trabalhado, a biblioteca era vista sobremaneira como um espaço de guarda e custódia dos acervos, devendo o bibliotecário zelar proteção do acervo sob sua responsabilidade. O espírito conservacionista e o fazer diante das necessidades imediatas caracteriza a Biblioteconomia como pré-científica, vista como uma espécie de arte ou ofício. Com o aumento dos registros impressos em papel, e de naturezas diferentes, como os livros e os periódicos, os procedimentos normativos e as técnicas tornamse mais elaboradas, convocando ainda a Bibliografia e a Biblioteconomia. Os catálogos deixam de ser listas de inventários como eram na Idade Média, abrindo espaço para os repertórios, bibliografias e bibliotecas portáteis capazes de melhor organizar e buscar as informações registradas.

A Biblioteconomia protocientífica é, portanto, assim caracterizada em decorrência da produção sistemática de um conhecimento teórico específico da Biblioteconomia, o que demonstra uma preocupação crescente em torno dessa matéria. Nesse momento as preocupações com o acervo e sua organização (catalogação e classificação) tornam-se cada vez mais complexas, o que demonstra a relação da produção do conhecimento da época com a instituição da biblioteca, assim como demonstra que os antigos procedimentos de ordenação das obras já não eram mais suficientes para esse momento. Desse modo, a criação de técnicas mais ou menos sofisticadas diante da necessidade de organizar o resultado de uma exacerbada produção documental caracteriza a Biblioteconomia protocientífica (PULIDO; MORRILAS, 2004). Em síntese, os séculos XVI-XVIII são marcados pela proliferação de obras, voltadas para regras, normas, esquemas de classificação e catalogação, ao lado dessas técnicas encontra-se o bibliotecário, um homem privilegiado socialmente, que passa paulatinamente a ser o responsável por disseminar e dar acesso à coleção organizada de livros e outros documentos.

\section{REFERÊNCIAS}

ARAUJO, C. A. A. Correntes teóricas da biblioteconomia. Revista Brasileira de Biblioteconomia e Documentação (Online), Brasília, v. 9, p. 41-58, 2013.

ALONSO, A. M. La evolucion del "systema bibliothecae" de la Compañia de Jesus y su influencia en la historia de la bibliografia española. 2006. Disponível em: <http://www.cervantesvirtual.com/nd/ark:/59851/bmcp2781>. Acesso em: 11 mar. 2014.

BÁEZ, F. História universal da destruição dos livros: das tábuas sumérias à guerra do Iraque. Rio de Janeiro: Ediouro, 2006.

BATTLES, M. A conturbada história das bibliotecas. São Paulo: Planeta do Brasil, 2003. 
BLAIR, A. As coletâneas de lugares comuns da renascença tardia. In: JACOB, Christian. $\mathbf{O}$ poder das bibliotecas: a memória dos livros no Ocidente. Rio de Janeiro: Ed. da UFRJ, 2000.

BRIQUET DE LEMOS, A. A. Biblioteca. In: CAMPELLO, B. S.; CALDEIRA, P. T. (Org.). Introdução às fontes de Informação. 2. ed. Belo Horizonte: Autêntica, 2008

BURKE, P. Problemas causados por Gutenberg: a explosão da informação nos primórdios da Europa moderna. Estudos Avançados, São Paulo, v. 44, n. 12, 2002.

BURKE, P. Uma história social do conhecimento: de Gutenberg a Diderot. Rio de Janeiro: Zahar, 2003.

BRUCHARD, D. O ex-libris. 2008. Disponível em: 〈http://www.escritoriodolivro.com.br/>. Acesso em: 11 jul. 2015.

CARDOSO, A. Livrarias e bibliotecas na Europa dos tempos modernos. 2013.

Disponível em: <ler.letras.up.pt/uploads/ficheiros/12350.pdf>. Acesso em: 25 de nov. 2014.

CHARTIER, R. A ordem dos livros: leitores, autores e bibliotecas na Europa entre os séculos XIV e XVIII. Brasília: Ed. da UnB, 1998.

FISCHER, R. S. História da leitura. São Paulo: Ed. da Unesp, 2006.

MARTINS, W. A palavra escrita: história do livro, da imprensa e da biblioteca. São Paulo: Ática, 2002.

MORALES LÓPEZ, V. La bibliotecología y estudios de la información: análisis históricoconceptual. Mexico: El Colegio de México, 2008.

NELLS, P. As origens arqueológicas da história das bibliotecas. In: JACOB, Ch. O poder das bibliotecas: a memória dos livros no Ocidente. Rio de Janeiro: Ed. da UFRJ, 2000.

PEREIRA, A. M.; SANTOS, P. L. Catalogação: breve histórico e contemporaneidade. Rio de Janeiro: Intertexto, 2014.

PULIDO, M. P.; MORILLAS, J. L. H. Teoria e nuevos escenarios de la Bibliotecología. Buenos Aires: Alfagrama, 2010.

PINHEIRO, A. V. (Org.). Biblioteconomia: a memória científica da Biblioteca Nacional Brasileira. Rio de Janeiro: Biblioteca Nacional, 2013. 
SERRAI, A. História da biblioteca como evolução de uma idéia e de um sistema. Revista da Escola de Biblioteconomia, Belo Horizonte, v. 4, n. 2, p. 141-161, 1975.

SOUZA, M. F. A. O ex-libris: significado, uso e história. Cadernos BAD, n. 3, 1963.

GARCIA VALENZUELA, H. Una aportación teórica a la evolución del concepto, término y definición de Biblioteconomía. Revista General de Información y Documentación, Madrid, v. 8, n.1, 1998.

Como citar este documento:

TANUS, Gabrielle Francinne. Da prática à produção do conhecimento: bibliotecas na modernidade $\mathrm{e}$ biblioteconomia protocientífica. Revista Digital de Biblioteconomia e Ciência da Informação, Campinas, SP, v. 13, n. 3, p. 546-560, set. 2015. ISSN 1678-765X. Disponível em: <http://periodicos. sbu.unicamp.br/ojs/index.php/rdbci/article/view/8639460>. Acesso em: 18 Set. 2015. 